\title{
Rancang Bangun Mesin Katinting Tenaga Surya
}

\author{
Jefta Ratela ${ }^{1}$ \\ Politeknik Kelautan dan Perikanan Bitung \\ e-mail: jeftaratela289@gmail.com \\ Novy Wijaya ${ }^{2}$ \\ Politeknik Kelautan dan Perikanan Bitung \\ Kaminton Tambunan ${ }^{3}$ \\ Politeknik Kelautan dan Perikanan Bitung
}

\begin{abstract}
ABSTRAK
Perkembangan peradaban manusia menimbulkan adanya perkembangan ilmu pengetahuan dan teknologi (IPTEK) yang terarah kepada teknologi canggih dan adanya peningkatan kebutuhan dan keinginan manusia baik dalam jumlah, variasi macamnya dengan meningkatkan kemampuan menyediakan atau menghasilkan sumberdaya manusianya. Sumber energi ramah lingkungan kian diburu seiring dengan makin meningkatnya kepedulian masyarakat terhadap lingkungan. Satu diantaranya adalah energi matahari. Ketergantungan yang sangat besar akan kehadiaran BBM ini menjadi bertambah besar dampaknya untuk itu berbagai alternatif ditawarkan untuk mengatasi ketergantungan ini, yaitu dengan penggunaan tenaga listrik dan motor listrik sebagai pengganti penggerak utama yang saat ini memakai motor bakar sebagai penggerak ketinting Penelitian ini bertujuan untuk merancang perahu ketinting yang menggunakan energi surya sebagai sumber tenaga penggerak.
\end{abstract}

\section{Kata kunci: Ketinting}

\begin{abstract}
The development of human civilization has led to the development of science and technology directed towards advanced technology and an increase in human needs and desires both in number, variety of kinds by increasing the ability to provide or produce human resources. Ecofriendly energy sources are increasingly being hunted along with increasing public awareness of the environment. One of them is solar energy. The enormous dependence on the presence of fuel has increased the impact for various alternatives to overcome this dependence, namely by using electric power and electric motors as a substitute for the main drivers that currently use combustion engines as driving forces. This study aims to design ketinting boats. which uses solar energy as a source of driving force.
\end{abstract}

Keywords: Ketinting

\section{PENDAHULUAN}

Perkembangan peradaban manusia menimbulkan adanya perkembangan ilmu pengetahuan dan teknologi (IPTEK) yang terarah kepada teknologi canggih dan adanya peningkatan kebutuhan dan keinginan manusia baik dalam jumlah, variasi macamnya dengan meningkatkan kemampuan menyediakan atau menghasilkan sumberdaya manusianya. Sumber energi ramah lingkungan kian diburu seiring dengan makin meningkatnya kepedulian masyarakat terhadap lingkungan. Satu diantaranya adalah energi matahari.

Mesin penggerak kapal merupakan suatu alat atau mesin yang digunakan sebagai motor penggerak kapal sehingga kapal dapat bergerak dari tempat yang satu ke tempat yang lain. Dalam sejarah perkembangan mesin penggerak kapal terdapat beberapa tipe yang mendominasi hingga kurun waktu tertentu, adalah sebagai berikut ;

$\begin{array}{llr}\text { 1.Reciprocating } & \text { Steam } & \begin{array}{r}\text { Engine } \\ \text { dunia ship }\end{array}\end{array}$


propulsion (sistem penggerak kapal) hingga sekitar tahun 1910-an. Keunggulannya adalah terletak pada pengaturan beban, khususnya untuk arah reversed (arah mundur) yang mana Reciprocating Steam Engine memberikan kemudahan serta lebih efisien pada range kecepatan rotasi tertentu agar match dengan kinerja screw propeller. Kelemahannya Reciprocating Steam Engine adalah pada instalasinya yang relatif berat, kebutuhan space yang besar, output power per cylinder-nya masih sangat terbatas.

\section{Marine (Steam) Turbines mesin} penggerak kapal yang pertama diinstal oleh Sir Charles Parsons ke kapal Turbinia pada tahun 1894, dengan kecepatan mencapai 34 knots.Kemudian turbines mengalami kemajuan pesat hingga pada tahun 1906, yang mana diaplikasikan sebagai tenaga penggerak untuk kapal perang HMS. Dreadnought dan kapal Atlantic Liner - Mauretania. Kebutuhan bahan bakar (fuel consumption) secara rata-rata untuk suatu Large Turbine adalah $0.30 \mathrm{~kg}$ per $\mathrm{kWh}$. Namun demikian, keunggulan segi ekonomis tersebut mengalami suatu tantangan dari sisi Non-reversible dan Rotational Speed, yang mana memerlukan pertimbangan teknis lebih lanjut.

3. Internal Combustion Engines (diesel engine) Mesin penggerak kapal yang digunakan dalam propulsi kapal, pada umumnya adalah Reciprocating engines yang beroperasi dengan prinsip-prinsip diesel (compression ignation) yang mana kemudian dikenal dengan nama Diesel Engines. Berbagai ukuran untuk Diesel Engines ini kemudian dibuat, mulai dari kebutuhan untuk pleasure boats hingga ke modern supertankers dan passenger liners.

4. Gas Turbine; Mesin penggerak kapal ini juga telah dikembangkan dalam dunia ship propulsion yangmana bahan bakar (fuel) dibakar melalui proses udara yang dikompresikan, dan gas panas hasil pembakaran tersebut digunakan untuk memutar turbine.Gas turbine umumnya diaplikasikan pada dunia kedirgantaraan, dan perkembangannya sangat tergantung pada teknologi metal yang mampu menahan terhadap tekanan dan temperatur yang tinggi. Keunggulan dari gas turbine ini terletak pada ukuran dan kapasitas power yang dihasilkan dibandingkan dengan tenaga penggerak lainnya.

MOTOR LISTRIK Mendominasi dunia ship propulsion (sistem penggerak kapal) hingga sekitar tahun 1910-an. Keunggulannya adalah terletak pada pengaturan beban, khususnya untuk arah reversed (arah mundur) yang mana Reciprocating Steam Engine memberikan kemudahan serta lebih efisien pada range kecepatan rotasi tertentu agar match dengan kinerja screw propeller. Kelemahannya Reciprocating Steam Engine adalah pada instalasinya yang relatif berat, kebutuhan space yang besar, output power per cylinder-nya masih sangat terbatas. Selain itu, Steam tidak dapat bekerja secara efektif pada tekanan relatif rendah. Serta kebutuhan fuel consumption yang tinggi, sebagai gambaran bahwa untuk triple-expansion engine maka memerlukan superheated steam yang mengkonsumsi bahan bakar (oil) hingga $\pm 0.70 \mathrm{~kg}$ per $\mathrm{kWh}$. 


\section{METODE PENELITIAN}

\subsection{Waktu dan tempat}

Penelitian ini didasarkan pada percobaan rancang bangun (eksperimen) dan terapan penggunaan energy surya sebagai sumber tenaga penggerak perahu ketinting. Setelah didapat prototype penggerak dengan tenaga surya kemudian dilakukan pengujian kemampuan daya dorong motor pengerak, kecepatan yang dapat dicapai dan ketahanan dalam penyimpanan energi. Pengambilan data awal dilakukan di dalam laboratorium Politeknik KP Bitung kemudian dilanjutkan di perairan.

\subsection{Analisis Data}

Analisa data dilaksanakan dengan observasi pada perahu ketinting. Dengan mencatat pemakaian daya listrik, pengujian kemampuan daya dorong motor pengerak sehingga menghasilkan kecepatan yang dapat dicapai (dengan asumsi beban kedua perlakuan sama) dan ketahanan dalam penyimpanan energi listrik. Nantinya akan dilakukan perbandingan perlakuan dengan menggunakan 2 ukuran balingbaling. Ukuran baling-baling 7 dan 9 yang dilakukan pengamatan dengan mencatat waktu pengambilan data.

Tabel 1. Perlakuan penggunaan balingbaling 7 dan 9 .

\begin{tabular}{|cl|c|c|}
\hline Parameter & $\begin{array}{c}\text { Baling } \\
\text { baling } \\
\text { ukuran 7 }\end{array}$ & $\begin{array}{c}\text { Baling } \\
\text { baling } \\
\text { ukuran 9 }\end{array}$ \\
\hline $\begin{array}{l}\text { 1. } \\
\text { 2. }\end{array}$ & $\begin{array}{l}\text { Kecepatan } \\
\text { daya listrik }\end{array}$ & & \\
\hline
\end{tabular}

\section{HASIL DAN PEMBAHASAN}

Penelitian ini bertujuan untuk merancang perahu ketinting yang menggunakan energi surya sebagai sumber tenaga penggerak. Di dalam kegiatan penelitian ini dilakukan beberapa penyesuaian dan modifikasi penggunaan komponen mesin yang ada di lapangan.

\section{Komponen penyusun Perahu Ketinting Tenaga Surya}

Panel Surya

Jenis monocrystalin, mempunyai efisiensi yang baik. Jenis ini dapat dikenali dengan warnanya yang kebiruan polos tanpa bercak.

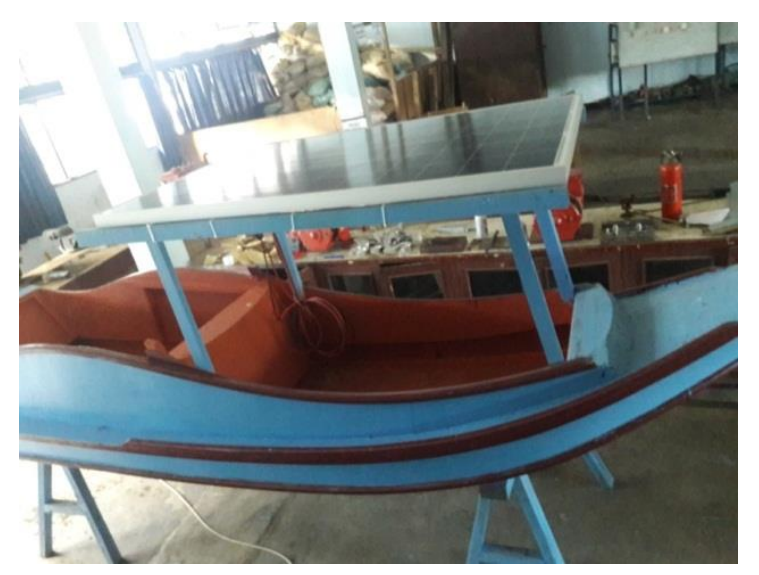

Gambar 3. Panel Surya

\section{Charge Controller}

Berfungsi untuk mengatur tegangan yang dikeluarkan ke baterai dan beban. Pengatur tegangan berfungsi untuk

- Mengamankan baterai dari kelebihan energi pengisian (over Charge)

- Mencegah pengeluaran energi yang berlebih (Over Discharge) yang berpotensi untuk memperpendek umur baterai.

- Sebagai pengaman pada kondisi arus pendek (Short Circuit) yang 
dapat merusak peralatan pembangkit.

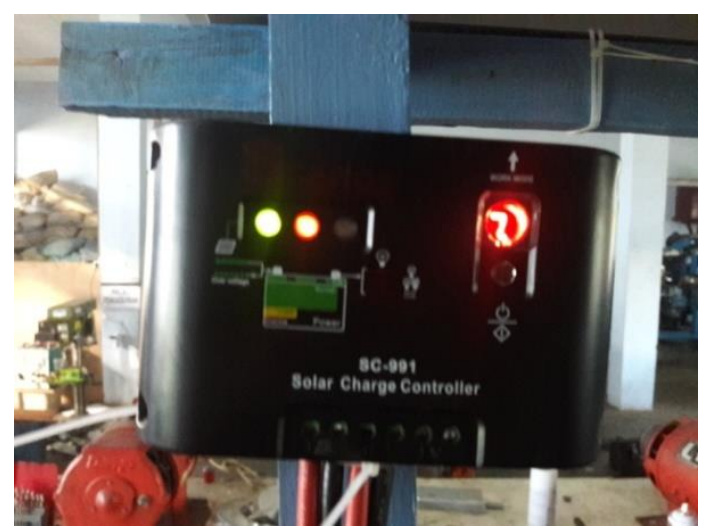

Gambar 4. Charge Controller

2. Bateray

Fungsi dari baterai adalah sebagai penyimpan energi. Pada saat panel surya berhenti bekerja akibat kekurangan sinar, baterai akan memberikan energinya ke beban listrik, menggunakan batrey basah merk Yuasa 100Ah.

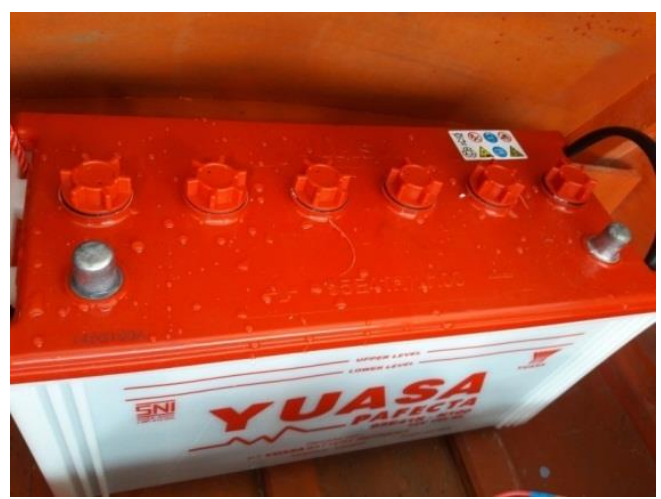

Gambar 5. Bateray

\section{Motor Penggerak}

Motor listrik sebagai penggerak perahu ketinting yang berasal dari motor start genset dan memiliki daya 700 watt.

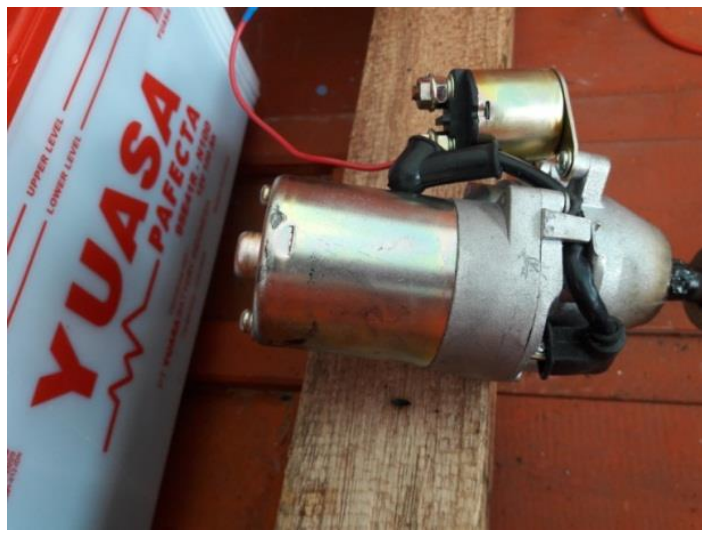

Gambar 6. Motor Listrik

4. Instalasi Tenaga Kapal

Instalasi Tenaga Kapal merupakan mekanisme penerus tenaga gerak dari motor listrik menuju baling-baling. Joint menggunakan ukuran 5/8. Baling baling menggunakan no 7

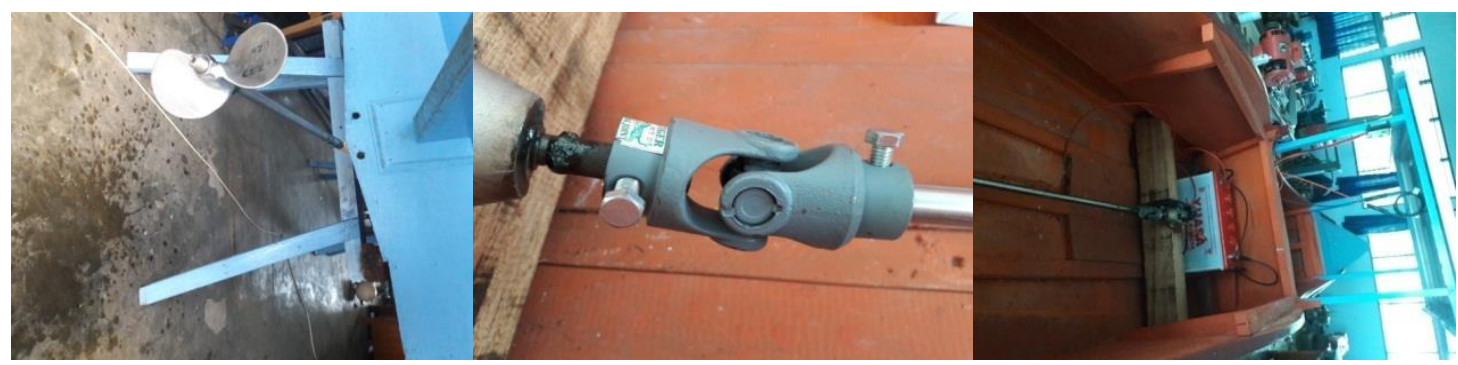

Gambar 7. Intalasi Tenaga Kapal 


\subsection{Pengujian Perahu Ketinting Tenaga Surya Di Lapangan}

Pengujian ketinting tenaga surya dilakukan di perairan pantai Selat Lembeh. Pengambilan data dilakukan dalam lima kali pada tanggal 15 Nov 2016, 17 Nov 2016, 22 Nov 2016, 24 Nov 2016 dan 25 Nov 2016.

Tabel 2. Data pengujian ketinting tenaga surya di lapangan

HARI 1

\begin{tabular}{|c|c|c|c|}
\hline $\mathrm{NO}$ & $J A M$ & $R P M$ & SUHU LINGKUNGAN \\
\hline & 10,00 & 505.3 & 36.3 \\
\hline & 11,00 & 503.7 & 37.6 \\
\hline & 12,00 & 550.3 & 38.3 \\
\hline & 14,00 & 510.5 & 37.8 \\
\hline & 15,00 & 490.4 & 36.2 \\
\hline & Rata2 & 512.04 & 37.24 \\
\hline $\mathrm{NO}$ & JAM & RPM & SUHU \\
\hline & 10,00 & 516.3 & 36.8 \\
\hline & 11,00 & 504.7 & 37.4 \\
\hline & 12,00 & 560.3 & 38.5 \\
\hline & 14,00 & 512.5 & 38.8 \\
\hline & 15,00 & 500.4 & 37.3 \\
\hline & Rata2 & 518.84 & 37.76 \\
\hline
\end{tabular}

HARI 3

\begin{tabular}{|r|r|r|c|}
\hline & JAM & RPM & SUHU \\
\hline & 10,00 & 509.3 & 36.6 \\
\hline & 11,00 & 508.7 & 36.8 \\
\hline & 12,00 & 540.6 & 38.3 \\
\hline & 14,00 & 510.3 & 38.8 \\
\hline & 15,00 & 498.4 & 36.8 \\
\hline & Rata2 & 513.46 & 37.46 \\
\hline
\end{tabular}

\begin{tabular}{|r|r|r|r|}
\hline & JAM & RPM & SUHU \\
\hline & 10,00 & 515.3 & 36.6 \\
\hline & 11,00 & 513.4 & 38.6 \\
\hline & 12,00 & 560.3 & 39.3 \\
\hline & 14,00 & 510.5 & 38.8 \\
\hline & 15,00 & 496.4 & 36.8 \\
\hline & Rata2 & 519.18 & 38.02 \\
\hline
\end{tabular}

\begin{tabular}{|r|r|r|c|}
\hline & JAM & RPM & SUHU \\
\hline & 10,00 & 505.3 & 36.3 \\
\hline
\end{tabular}




\begin{tabular}{|l|r|r|r|}
\hline & 11,00 & 513.7 & 37.6 \\
\hline & 12,00 & 570.3 & 38.6 \\
\hline & 14,00 & 510.5 & 38.8 \\
\hline & 15,00 & 490.6 & 37.2 \\
\hline & Rata2 & 518.08 & 37.7 \\
\hline
\end{tabular}
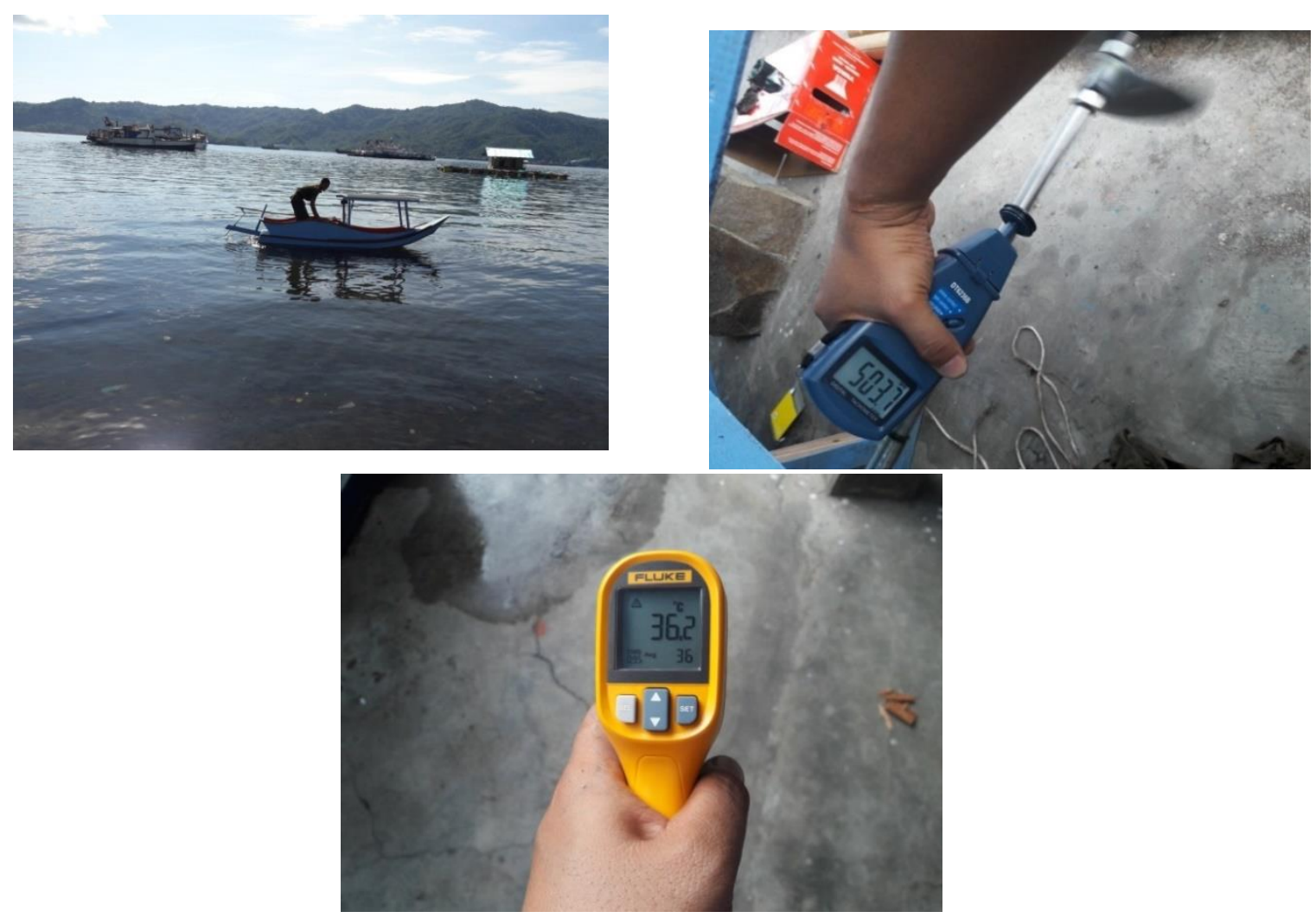

Gambar 8. Pengambilan data di lapangan.

\section{KESIMPULAN}

1. Dari percobaan yang dilakukan, dapat disimpulkan bahwa Rancang Bangun Ketinting Tenaga Surya dapat dilakukan dan operasional.

2. Penelitian ini masih berupa penelitian pendahuluan yang perlu dilakukan penelitian lanjutan untuk menentukan besarnya spesifikasi motor penggerak, ukuran panel surya dan kebutuhan batrey guna mendapatkan rancangan yang maksimal.

\section{DAFTAR PUSTAKA}

Adji, Suryo Widodo; [1995]; “Evaluasi Teknis Sistem Propulsi Motor Sailing Boat Maruta Jaya 900"; Laporan Penelitian TSP-FTK ITS; Surabaya.

Arismunandar, W. (1998) Pedoman untuk Mencari Sumber Kerusakan, Merawat dan Menjalankan Kendaraan Bermotor. Jakarta : Pradnya Paramita. 
Arismunandar, W; Wiranto dan Tsuda, K. (2002). Motor Diesel Putaran Tinggi. Jakarta : PT Pradnya Paramita

Adji, Suryo Widodo; [1995]; “Evaluasi Teknis Sistem Propulsi Motor Sailing Boat Maruta Jaya

900"; Laporan Penelitian TSP-FTK ITS; Surabaya.

Berahim, Hamzah Ir.; [1991]; "Pengantar Teknik Tenaga Listrik"; Andi Offset; Yogyakarta.

Dunia Listrik, Motor ListrikAC Satu

Fasa, http://dunialistrik.blogspot.com/2009/04/ motor-listrik-ac-satu-fasa.html

Hadi, E. Sasmito; [1998]; "Penggunaan Energi Surya Sebagai Sumber Alternatif Penggerak

Kapal"; skripsi FTP-UNPATTI; Ambon.

Mitra Hebat Teknik, Motor Listrik Satu Fasa, http://maintenace.wordpress.com /2009/10/25/ motor-listrik-acsatu-fasa.

Nasir, M. (1985) Metode Penelitian. Ghalia Indonesia. Jakarta. 597 p.

Prinsip kerja motor ac dan dc, http://metaphysicalparadox.blogspot.com/2013/03/p rinsip-kerja-motor-ac-dandc.html

Tachibana, Y. dkk; [1985]; "Diesel Electric Propulsion System of Ice Breaker 'SHIRASE' '; Jurnal on
Bulletin of The M.E.S.J. Vol. 13 No. 1; Jepang.

Zuhal; [1991]; "Dasar Tenaga Listrik"; Penerbit ITB; Bandung. 


\section{THIS PAGE IS INTENTIONALLY LEFT BLANK}

